\title{
Reference Framework for E-participation Projects
}

\author{
Sabrina Scherer and Maria A. Wimmer \\ University of Koblenz-Landau, Research Group E-Government, \\ Universitaetsstrasse 1, 56070 Koblenz, Germany \\ \{scherer, wimmer\}@uni-koblenz.de \\ http://www. uni-koblenz-landau.de
}

\begin{abstract}
Accommodating the various requirements from distinct perspectives in e-participation calls for a holistic engineering approach for e-participation systems analysis and design. This paper presents research results towards a reference framework for e-participation projects. An analysis of procedural models for e-participation and enterprise architectures in the context of e-participation shows that a holistic approach is necessary. A sophisticated and holistic engineering approach for e-participation in the form of a reference framework is seen as a solution to support e-participation projects development and implementation. The reference framework consists of different concepts supporting each other: dimensions that build the scope of an e-participation project, a domain meta model, a procedural reference model, and a library with requirements, reference models and building blocks for e-participation.
\end{abstract}

Keywords: E-participation, Reference Framework, Reference Model.

\section{Introduction}

Information and Communication Technology (ICT) is to be considered an enabler and facilitator for political participation, but one cannot expect that technology per se impacts political decision making and active citizen participation in political processes. Recent research results in e-participation give ground that possibilities of using ICT for political participation have not yet been sufficiently exploited [12. Many e-participation projects suffer from planning citizen participation along the whole policy life-cycle of political decision-making [1], i. e. ensuring that the voices raised through e-participation are heard by political decision makers and have an impact on final decisions at political level 4]. The success of innovative e-participation solutions depends - among other challenges - heavily on the organizational planning and the incorporation of such initiatives into the daily routines of political processes along the different stages in the policy life-cycle. Introducing e-participation does not only require the adaptation of given participation processes. It often demands introduction of new participation facilities into traditional political processes, which calls for a holistic engineering approach for e-participation systems analysis and design. Such an approach can 
be built upon reference models for e-participation. Reference models are generic conceptual models that formalize recommended practices for a certain domain with three characteristics [5, p. 4]: (1) A reference model provides best practices. (2) A reference model is valid for a class of domains. (3) Reference models can be understood as blueprints for information systems development. Thus a reference model is a conceptual framework that could be reused in a multitude of information systems projects. Reference models serve for several purposes. They can be utilised [13, p. 484f]

- to build a framework for the identification, development, and coordination of related standards and to facilitate communication among the stakeholders.

- to develop more specialized models for support.

- to obtain a so-called reference architecture, so be mapped onto a collection of software components and data flows between those components.

- to enable the use of an architecture-based development process.

The paper at hand presents research results towards a reference framework for e-participation that structures the access to reference models for the domain e-participation.

The paper is structured as follows. In the next section related work is reviewed: procedural models for e-participation, and the application of Enterprise Architecture (EA) frameworks in the context of e-participation is reflected. This research is used as a starting point to develop a reference framework for e-participation. The research approach is presented in section 3 Section 4 sums up the needs for and presents the reference framework for e-participation. Finally conclusions are drawn.

\section{Related Work}

\subsection{Procedural Models and Guidelines for E-participation}

Existing procedural models for e-participation, which can provide a framework and guideline for e-participation projects, are focussing on different aspects of e-participation. Based on desktop research for e-participation models, seven procedural models have been selected to be investigated in this section. Table 1 gives an overview of the procedural models. The column Id, Name and Source indicates first an identifier for easier handling of the different approaches in the paper. It further shows the name of the procedural model (or English translation) and source reference. The column Level specifies if the model focuses on local, regional, national, European, or general level. The column Strategy indicates if the model is related to bottom-up or top-down approaches. The column Area names the e-participation area which is covered by the corresponding procedural model (e.g. participatory budgeting). The procedural models introduced in table 1 are briefly described subsequently. Figure 1 visualises the different steps and activities described in the procedural models for e-participation.

(a) Phang and Kankanhalli present a framework of ICT exploitation for e-participation initiatives. They examine the suitability of various information 
Table 1. Overview of procedural models for e-participation

\begin{tabular}{|l|l|l|l|}
\hline Id, Name and Source & Level & Strategy & Area \\
\hline $\begin{array}{l}\text { (a) A three-step procedure for e-participation } \\
\text { initiative implementation [14] }\end{array}$ & General & $\begin{array}{l}\text { Top-down, } \\
\text { bottom-up }\end{array}$ & General \\
\hline $\begin{array}{l}\text { (b) Implementation model for sustainable } \\
\text { e-participation [7] }\end{array}$ & General & $\begin{array}{l}\text { Top-down, } \\
\text { bottom-up }\end{array}$ & General \\
\hline $\begin{array}{l}\text { (c) Guideline for online consultation: practi- } \\
\text { cal recommendations for the involvement of } \\
\text { citizens over the Internet [10] }\end{array}$ & Top-down & $\begin{array}{l}\text { Online con- } \\
\text { sultation }\end{array}$ \\
\hline $\begin{array}{l}\text { (d) Standards for public participation: prac- } \\
\text { tice guide 3] }\end{array}$ & National & Top-down & General \\
\hline $\begin{array}{l}\text { (e) Procedure of Cologne's participatory bud- } \\
\text { geting project 23] }\end{array}$ & Local & Top-down & $\begin{array}{l}\text { Participatory } \\
\text { Budgeting }\end{array}$ \\
\hline $\begin{array}{l}\text { (f) Guideline for local e-participation projects } \\
\text { 26] }\end{array}$ & Local & Top-down & General \\
\hline $\begin{array}{l}\text { (g) A collaboration pattern language for e- } \\
\text { participation: a strategy for reuse [2] }\end{array}$ & General & $\begin{array}{l}\text { Top-down, } \\
\text { bottom-up }\end{array}$ & General \\
\hline
\end{tabular}

and communication tools for the achievement of e-participation objectives [14]. Phang and Kankanhalli transmit offline participation techniques analysed by Glass [6] in order to technically support them. Phang and Kankanhalli also present a process for implementing e-participation initiatives consisting of the following three steps [14]: identification of the objective, choosing the best participation techniques, and choosing the electronic tools which support the participation techniques and thereof the achievement of the objectives.

(b) Islam presents a sustainable e-participation implementation model [7]. This iterative procedural model describes seven consecutive phases: policy and capacity building, planning and goal setting, programs and contents development, process \& tools, promotion, participation, and post implementation analysis 7 .

(c) Koop presents an extensive practical guideline for on-line consultations, which aims to give recommendations about how to incorporate citizens with the Internet [10]. This guideline compromises recommendations when online consultations are useful, which actions need to be undertaken by the project team, which formats can be used when and which electronic tools are used. The practical oriented implementation guideline for online citizens consultations published in [10] comprises four phases: identification of the objectives and conditions, design of the procedure, implementation of the consultation, evaluation and conclusion. For each phase questions are defined that need to be answered in order to design an e-participation project.

(d) The guide about standards for public participation published by the Federal Chancellery of the Republic of Austria and Ministry for Live wants to define recommendations for public participation in general. The guide provides a decision help for public participation during the development of policies, plans, 


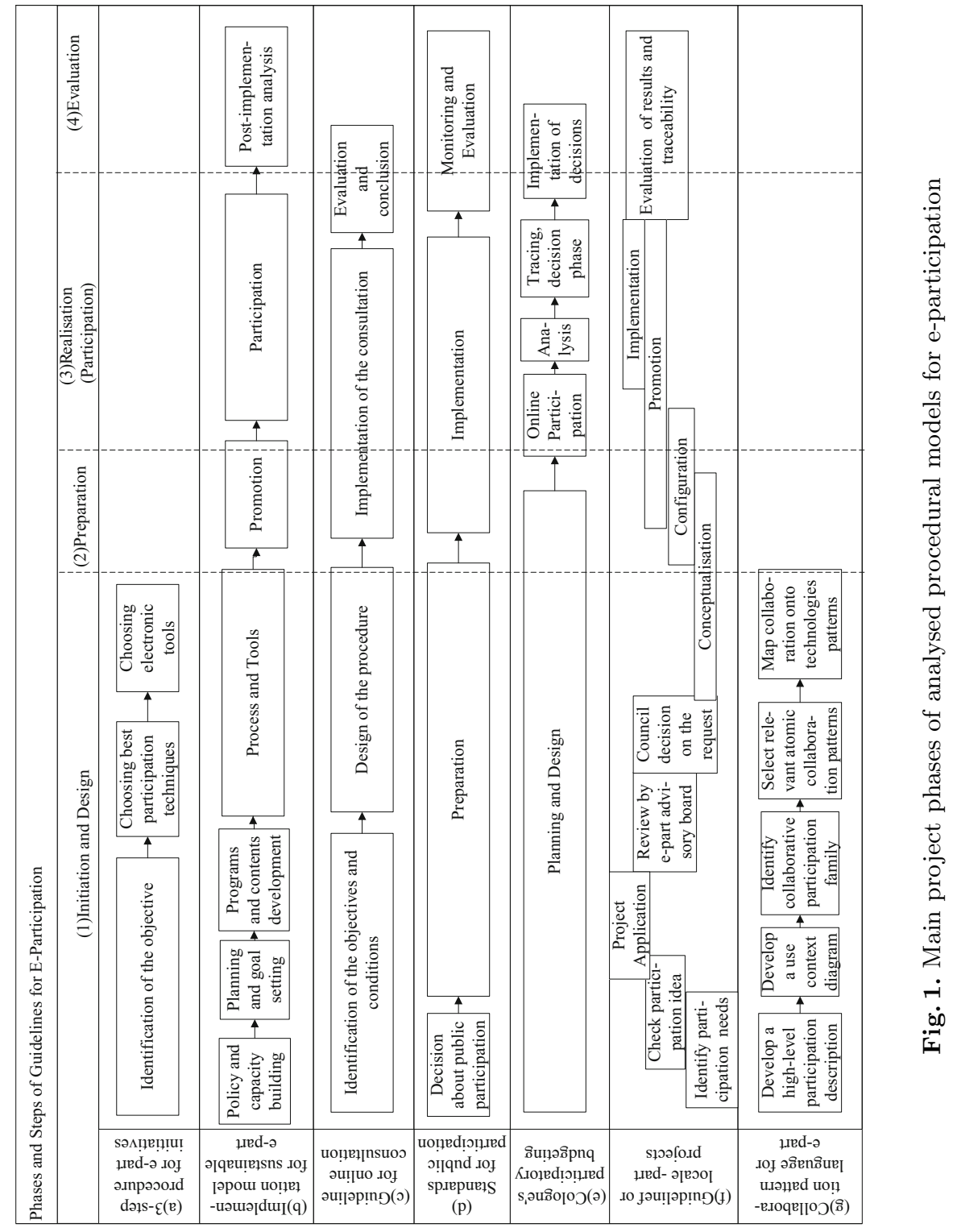


programmes and legal acts and differentiates three further phases preparation, implementation and monitoring (in regards to traceability) and evaluation of the participation process. The implementation of participation process gives detailed recommendations regarding the participation areas information, consultation, and cooperation.

(e) The procedural model of the participatory budgeting approach in Cologne is introduced in the evaluation report of the project [23]. It encompasses the following phases: planning and design, online participation, participation analysis, tracing and decision phase, implementation of decisions. This approach takes the monitoring of decision making in regards to impact analysis into consideration. It details participation processes related to participation areas information, consultation and cooperation.

(f) Based on the participatory budgeting approach in Cologne and other German cities, Wehner, Gölz and Märker propose a guideline for local e-participation projects [26]. This approach details a guideline for top-down e-participation projects initiated by local administrations. In contrast to the other approaches, they take the decision for an e-participation project and administrative tendering procedure into account before an e-participation project initiated by administrations can start. Wehner, Gölz and Märker propose an approach with the following phases that partly overlap: identify participation needs, check participation idea, project application, review by e-participation advisory board, council decision on the request, conceptualisation, configuration, promotion, implementation, and evaluation of results and traceability. Wehner, Gölz and Märker model parts of the procedure as business processes using event-driven process chains.

(g) Ali et. al. propose a collaboration pattern language to design architectures for e-participation systems [2]. The aim is to provide a guidance to help the designers of e-participation systems to choose suitable collaborative technologies. The proposed pattern language is based on the work in the areas of collaboration engineering and software engineering. The five phases proposed are focussing on the selection of adequate collaboration patterns: develop a high-level participation description, develop a use context diagram, identify collaborative participation family, select relevant atomic collaboration patterns, and ap collaboration patterns onto technologies patterns. The approach focuses on the design phase of an e-participation project.

The investigated procedural models focus on different tasks necessary to implement an e-participation project; none of them provides a holistic approach. To provide a holistic approach to manage the diversity of tasks in complex system developments, Enterprise Architecture (EA) frameworks are used in commercial areas and e-government (see e.g. [8] ) to coordinate and manage relevant development tasks. The next section introduces an analysis about how EA frameworks are applicable for e-participation systems analysis and design.

\subsection{Enterprise Architecture Frameworks}

EA is a concept of Information Systems, which gives guidance in complex sociotechnical systems development along three dimensions: (i) phases of systems 
development, (ii) levels of abstraction combined with dedicated stakeholder (or owner) views, and (iii) distinct viewpoints on concepts such as data, functions, people, motivation, etc. EA frameworks define how an EA can be developed and implemented. Multiple approaches for EA frameworks exist. Since 1984 more than 20 EA frameworks have been developed and published [20, which are provided by different parties and serve different purposes. In 18 the application of three EA frameworks - Zachman Framework [28, TOGAF (The Open Group Architecture Framework) [25], and ARIS (Architecture of Integrated Information Systems) [15] - in the life-cycle of e-participation projects is analysed. EA frameworks are not supposed to ensure the success of e-participation. They are rather seen as a means to support organisational and sustainable implementation of e-participation projects. Coherences with different procedural models for e-participation can be observed. EA frameworks provide a concept to support the implementation of e-participation projects [18]. Point of criticism is that the complexity of most EA frameworks can be seen as rather high. Organizations are often struggling to get control over their ICT landscape 8. The single use of EA frameworks in order to establish e-participation in an organisation might be immoderate. Therefore best practices in the form of reference models might be a solution to support e-participation projects [18: TOGAF provides with the Architecture Development Method (ADM) an extensive engineering approach with a high focus on monitoring the overall process. ADM is seen as an appropriate approach to support project implementation in exploiting possibilities of using ICT for political participation through all phases of an e-participation project. In order to address relevant questions during the initiation of an e-participation project, the use of the dimensions of the Zachman Framework is recommended.

\section{Research Approach for Developing the Reference Framework}

The methodological approach to develop the reference framework for e-participation is based upon the reference modelling methodology described in [21]. As a starting point of the methodology the problem scope is defined. A number of problem categories are described that are relevant when an e-participation project is implemented. The problem categories have been identified based on studies in e-participation projects i.e. LEX-IS1, VoicE and VoiceS2 (in [17 a historical description of research undertaken is provided), and others as e.g. the Cologne Participatory Budgeting Project 3 . Based on the problem definition, the next step is to develop the reference model framework. The reference model framework reflects the coarse structure of the reference models [2124]. It serves

\footnotetext{
${ }^{1}$ Enabling the participation of youth into the legislation of national parliaments, see http://www . lex-is.eu

${ }^{2}$ Regional model for e-participation in the European Union with integration of social networks, serious games and semantics, see http://www.give-your-voice.eu/

${ }^{3}$ https://buergerhaushalt. stadt-koeln.de
} 
as a master reference model that supports the modelling and puts on a standardisation of terms and model building blocks [21]. The development of the reference framework for e-participation is an iterative process. The reference framework is refined in different iterations based on desk research, expert surveys and experiences from project participation. Requirements of the reference framework are derived based on desk research, problem categorisation and a survey among e-participation researchers and practitioners. The requirements are to be understood in addition to general requirements for reference frameworks and models. Finally, the reference framework for e-participation is completed. The reference framework needs to be extended with interconnections between the reference models and with other reference frameworks [21].

\section{Reference Framework for E-participation}

The investigation of procedural models for e-participation unveils that there is no solution that takes into account all relevant tasks for an e-participation project. The integration of different tasks and existing technical systems (in order to support the back-office of an organisation) is under-represented in particular. EA frameworks might be a solution to overcome these challenges of e-participation projects. But the complexity of EA frameworks [18] hinder the exploitation of them in e-participation contexts.

A sophisticated and holistic engineering approach for e-participation in the form of a reference framework is seen as a solution to support e-participation projects development and implementation with customised good practice examples. The main purpose of the reference framework is to facilitate the understanding of what is required to implement an e-participation project. It should provide a lightweight approach by providing solutions for different kinds of e-participation projects and various types of organisations, which build up e-participation projects. The reference framework for e-participation aims to support different target groups to communicate with other project actors, e.g. politicians, system developers, moderators - i.e. persons with different technical and political background and having a different perspective on an e-participation project.

The reference framework consists of different concepts supporting each other (see Figure 2): 1. Dimensions that build the scope of an e-participation project 2. Domain meta model for e-participation 3. Procedural reference model for e-participation 4. Library with requirements, reference models and building blocks for e-participation. The big arrows in Figure 2 show that from one part of the reference framework the results of another part of the reference framework are accessed. The concepts are briefly introduced in the subsequent sections.

\subsection{Dimensions}

The Dimensions in the reference framework for e-participation are based upon the dimensions introduced in the Zachman Framework 28]. Applied to e-participation, the areas can be described as follows [18]: 


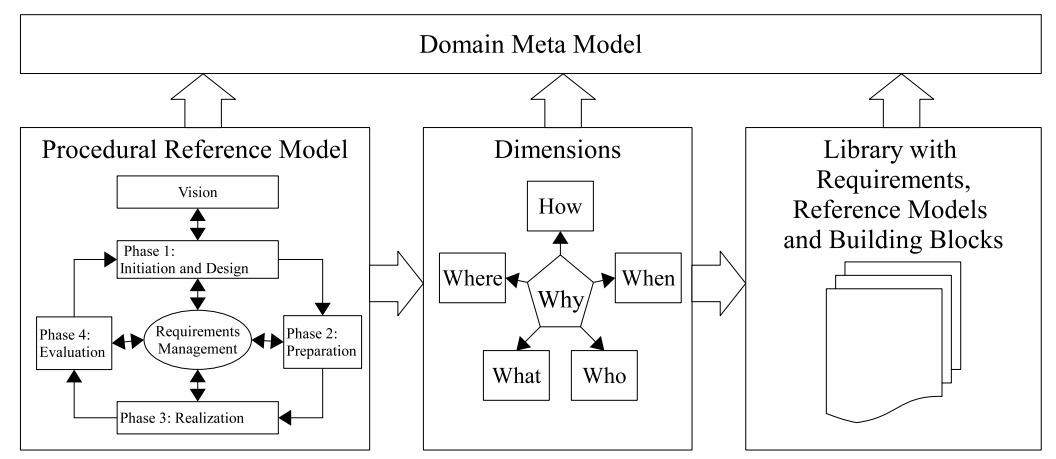

Fig. 2. Reference framework for e-participation

1. Motivation (Why): This dimension concerns the translation of e-participation goals and strategies into specific ends and means. This can be expanded to include the entire set of constraints that apply to the efforts. Principles of participation are defined, too. In an e-participation project, all other activities should start from this point.

2. Time (When): This dimension requires careful planning of when certain tasks are to be performed, what dependencies exist (e.g. a consultation should be made at a point where impact on a decision to be made is still possible).

3. People (Who): This dimension identifies and describes the stakeholders involved into the e-participation project, i. e. active or inactive actors. Following the definition in ISO 10006, stakeholders of a project are those persons who are interested in the project or are affected by the project.

4. Data (What): This dimension addresses understanding of, and dealing with data in the e-participation system. Such data may concern particular topics to be discussed in the e-participation endeavour, the political environment, the legislative procedures, participation procedures, estimated impact etc.

5. Network (Where): This dimension is concerned with the geographical distribution of the legislative and political processes, participation activities and involved actors and institutions.

6. Function (How): This dimension describes the process of translating the mission of the e-participation project successively into more detailed definitions of its operations. The legislative procedures are analysed, possible points for participation are identified and participation processes are planned.

The dimensions control the access to the other parts of the reference framework during the implementation of a particular e-participation project.

\subsection{Domain Meta Model for E-participation}

The use of a Domain Meta Model for E-participation in the reference framework bases on the concept of a content meta model presented in TOGAF 25. It defines a formal structure of terms used in the reference framework to ensure consistency and provide guidance for users of the reference framework. The domain 
meta model for E-participation bases on the Domain Model for E-participation by Kalampokis et al. [9]. This model is based on an e-participation framework by almost the same authors, which consists of four layers: democratic processes, participation areas, participatory techniques, categories of tools and ICT technologies [22]. The domain model for e-participation aims to represent the most important aspects of e-participation and their interrelations. The authors divide the domain into three areas: actors, participation processes, and information and communication tools. These areas are further detailed in separate models and finally brought together to visualize the key interrelations among aspects of the three areas. Kalampokis et al.'s model demonstrates the complexity of the domain. Further research is necessary in order to define a domain meta model for e-participation and align it with the dimensions of the reference framework for e-participation.

\subsection{Procedural Reference Model for E-participation}

The Procedural Reference Model shall provide guidance in order to manage tasks, which are necessary for implementing an e-participation project (see [18] for description of tasks). The steps in the different procedural models can be categorised into four main phases of an e-participation project [18]: (1) initiation and design, (2) preparation, (3) realisation (participation) and (4) evaluation. In figure 1 these four phases are visualised with the indication of how the e-participation models investigated in section 2.1 implement these phases. In addition to these phases, an e-participation project should be accompanied by continuous requirements management (based on the TOGAF ADM 25]: requirements specification as to-be specification in phase (1), preparation and realisation based on requirements in phases (2) and (3), evaluation of results (to-be state) against the requirements in phase (4). The resulting outline of the procedural reference model for e-participation is visualised in figure 3 .

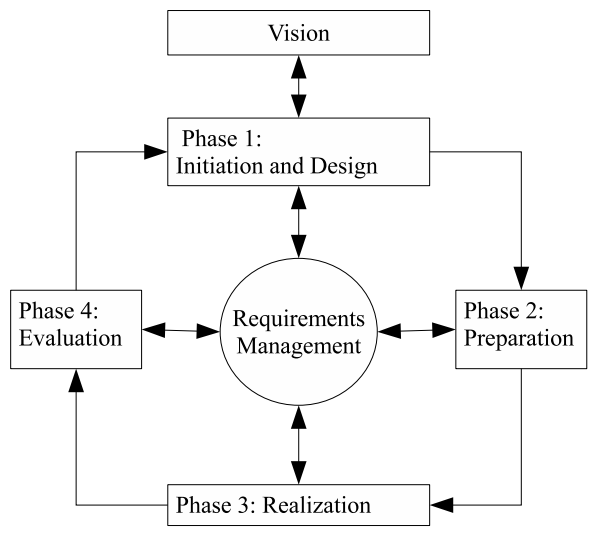

Fig. 3. Procedural reference model for e-participation 
The procedural reference model for e-participation is structured along the four main phases identified before for implementing an e-participation project. In each phase e-participation project implementation steps are detailed using the following scheme: (a) description of the step, (b) relevant literature, (c) activities, and (d) results. It is closely following TOGAF ADM, whereby it reduces complexity by providing guidance in the form of reference models and building blocks for the domain e-participation (see section 4.4).

\subsection{Library with Requirements, Reference Models and Building Blocks for E-participation}

A Library with Requirements, Reference Models and Building Blocks supports an e-participation project with recommended practices for e-participation processes and tools. A requirement means (following TOGAF [25]) a quantitative or qualitative statement of need that must be met by the e-participation project or particular supporting processes or supporting tools. A requirements library contains requirements, assumptions, constraints and gaps relevant to implement an e-participation project. Reference participation process models serve as a guidance how to implement the participation activities based on a particular objective or goal. Thereby, the procedural reference model for e-participation is supported by reference participation process models modelled. Suitable process models are selected from the library based on the selected dimensions of the reference framework for the particular e-participation project. E-participation processes have so far not been extensively modelled and standardised. There is a lack of reference models for process patterns and process chains describing common processes in e-participation [16] even if first models and patterns exist (see e.g. [21926]). Further research is necessary to identify and model reference participation processes that support different e-participation areas as e.g. consultation, participatory budgeting, petitioning. In order to ground the reference model empirical e-participation project evaluation studies is used (as e.g. 27 11]). In addition a toolbox of technical building blocks is included to support e-participation and a reference architecture to combine these blocks efficiently. Such a toolbox supports the use of standardised participation processes. Thereby, technical requirements such as interoperability of services [16] need to be considered.

\section{Conclusion}

This paper presented research results towards the development of a reference framework for e-participation. Based on project experiences and an extensive desk research the main phases of e-participation project development and implementation have been identified. Further research analysed how far EA frameworks can support e-participation projects and where the limitations are. The development of a reference framework for e-participation was argued as a means to support the organizational planning of e-participation projects and the incorporation of such initiatives into the daily routines of the different stages in the 
policy life-cycle. The paper presented a reference framework for e-participation to support these purposes. The use of the reference framework does not automatically enhance citizens participation in e-participation projects, but makes an important step towards the flawless implementation of e-participation projects.

\section{References}

1. Albrecht, S., Kohlrausch, N., Kubicek, H., Lippa, B., Märker, O., Trénel, M., Vorwerk, V., Westholm, H., Wiedwald, C.: eParticipation - Electronic Participation of Citizens and the Business Community in eGovernment. Study on Behalf of the Federal Ministry of the Interior (Germany), Division IT 1 (January 2008), http:// www.ifib.de/publikationsdateien/study_e-participation_engl.pdf

2. Ali, H., Macaulay, L., Zhao, L.: A Collaboration Pattern Language for eParticipation: a Strategy for Reuse. In: Proceedings of the 9th European Conference on e-Government, pp. 29-38. Academic Publishing International, London (2009)

3. Arbter, K.: Standards der Öffentlichkeitsbeteiligung. Praxisleitfaden, Bundeskanzleramt Österreich und lebensministerium.at, Wien (January 2011), www . partizipation.at/standards_oeb.html

4. Bicking, M., Triantafillou, A., Koussouris, S., Wimmer, M.A.: Lessons from Monitoring and Assessing EC-funded eParticipation Projects: Citizen Engagement and Participation Impact. In: Proceedings of IST Africa 2011 Conference, digital proceedings as CD (2011)

5. Fettke, P., Loos, P.: Perspectives on Reference Modeling. In: Reference Modeling for Business Systems Analysis, pp. 1-21. IGI Global (2006)

6. Glass, J.J.: Citizen Participation in Planning: The Relationship Between Objectives and Techniques. Journal of the American Planning Association 45(2), 180-189 (1979)

7. Islam, M.S.: Towards a sustainable e-Participation implementation model. European Journal of ePractice 5 (October 2008), http://www .epractice.eu/files/5. 3. pdf\&ei=kZFMS421L8LC4gbwj8zmQQ sa=X\&oi=nshc\&resnum=1\&ct=result\&cd=2\& ved+OCBEQzgQoAQ\&usg=AFQjCNHt3sd2jcfkmxmNWOYxvEOuyg94Zw

8. Janssen, M.: Sociopolitical Aspects of Interoperability and Enterprise Architecture in E-Government. Social Science Computer Review (January 2011)

9. Kalampokis, E., Tambouris, E., Tarabanis, K.A.: A Domain Model for eParticipation. In: Mellouk, A., Bi, J., Ortiz, G., Chiu, D.K.W., Popescu, M. (eds.) ICIW, pp. 25-30. IEEE Computer Society, Los Alamitos (2008)

10. Koop, A.: Leitfaden Online-Konsultation: Praxisempfehlungen für die Einbeziehung der Bürgerinnen und Bürger über das Internet. Leitfaden, Bertelsmann Stiftung (2010), http://www.online-konsultation.de/leitfaden

11. Kubicek, H., Lippa, B., Koop, A. (eds.): Erfolgreich beteiligt? Nutzen und Erfolgsfaktoren internetgestützter Bürgerbeteiligung - Eine empirische Analyse an 12 Fallbeispielen. Verlag Bertelsmann Stiftung, Gütersloh (2011)

12. Macintosh, A.: eParticipation in Policy-making: the Research and the Challenges. In: Cunningham, P., Cunningham, M. (eds.) Exploiting the Knowledge Economy: Issues, Applications, Case Studies, pp. 364-381. IOS Press, Amsterdam (2006)

13. Mišić, V.B., Zhao, J.L.: Evaluating the Quality of Reference Models. In: Laender, A., Liddle, S., Storey, V. (eds.) ER 2000. LNCS, vol. 1920, pp. 484-498. Springer, Heidelberg (2000), http://dx.doi.org/10.1007/3-540-45393-8_35 
14. Phang, C.W., Kankanhalli, A.: A framework of ICT exploitation for e-participation initiatives. Communications of the ACM 51(12), 128-132 (2008)

15. Scheer, A.W.: ARIS-House of Business Engineering: Konzept zur Beschreibung und Ausführung von Referenzmodellen. In: Becker, J., Rosemann, M., Schütte, R. (eds.) Entwicklungsstand und Entwicklungsperspektiven der Referenzmodellierung. Arbeitsberichte des Instituts für Wirtschaftsinformatik, vol. 52, pp. 3-15. Institut für Wirtschaftsinformatik der Westfälischen Wilhelms-Universität Münster (1997)

16. Scherer, S., Liotas, N., Wimmer, M.A., Tambouris, E., Tarabanis, K.: Interoperability Requirements, Recommendations and Standards in E-Participation. In: Charalabidis, Y. (ed.) Interoperability in Digital Public Services and Administration: Bridging E-Government and E-Business, ch. 6, pp. 95-117. IGI Global (May 2011)

17. Scherer, S., Wimmer, M., Ventzke, S.: Hands-On Guideline for E-Participation Initiatives. In: Janssen, M., Lamersdorf, W., Pries-Heje, J., Rosemann, M. (eds.) EGES 2010 and GISP 2010. IFIP Advances in Information and Communication Technology, vol. 334, pp. 49-61. Springer, Heidelberg (2010), http://dx.doi.org/ 10. 1007/978-3-642-15346-4_5

18. Scherer, S., Wimmer, M.A.: Analysis of Enterprise Architecture Frameworks in the Context of E-Participation. In: tba (ed.) Proceedings of the 12th Annual International Conference on Digital Government Research (dg.o 2011) Digital Government Innovation in Challenging Times. p. tba. ACM International Conference Proceedings. ACM digital library (June 2011)

19. Scherer, S., Wimmer, M.A., Ventzke, S.: Modellierung von Prozessen für EPartizipation in BPMN. In: Fischer, S., Maehle, E., Reischuk, R. (eds.) Informatik 2009, Im Focus das Leben. LNI, vol. 154, pp. 1804-1813. Gesellschaft für Informatik, Köllen Druck+Verlag GmbH, Bonn (2009)

20. Schönherr, M.: Enterprise Architecture Frameworks. In: Aier, S., Schönherr, M. (eds.) Enterprise Application Integration - Serviceorientierung und nachhaltige Architekturen, Enterprise Architecture, vol. 2, pp. 3-48. Gito-Verlag, Berlin (2004)

21. Schütte, R.: Grundsätze orgnungsgemässer Referenzmodellierung, Neue betriebswirtschaftliche Forschung, vol. 233. Gabler, Wiesbaden (1998)

22. Tambouris, E., Liotas, N., Kaliviotis, D., Tarabanis, K.: A framework for scoping eParticipation. In: dg.o 2007: Proceedings of the 8th Annual International Conference on Digital Government Research, pp. 288-289. Digital Government Society of North America (2007)

23. Taubert, N., Krohn, W., Knobloch, T.: Evaluierung des Kölner Bürgerhaushalts. Tech. rep., Universität Bielefeld im Auftrag der Stadt Köln (September 2010)

24. Thomas, O., Hermes, B., Loos, P.: Reference Model Based Management. International Journal of Event Management Research 4(1), 38-57 (2008)

25. TOGAF Version 9. TOGAF Series, The Open Group, 9 edn. Van Haren Publishing, Zaltbommel (January 2009), http://www . vanharen.net

26. Wehner, J., Gölz, S., Märker, O.: Leitfaden für kommunale E-PartizipationsVerfahren. Tech. rep., Fraunhofer IAIS, Zebralog (2009)

27. Whyte, A., Macintosh, A.: Analysis and evaluation of e-consultations. e-Service Journal 2(1) (2003)

28. Zachman, J.A.: A framework for information systems architecture. IBM Systems Journal 26(3), 277-293 (1987) 